\title{
IMPACT OF THERMOMECHANICAL AGING ON ALLOY 625 HIGH TEMPERATURE MECHANICAL PROPERTIES
}

\author{
Lorena Mataveli Suave ${ }^{1,2}$, Denis Bertheau ${ }^{1}$, Jonathan Cormier $^{1}$, Patrick Villechaise ${ }^{1}$, Aurélie \\ Soula ${ }^{3}$, Zéline Hervier ${ }^{4}$, Florence Hamon ${ }^{1}$ and Johanne Laigo ${ }^{5}$ \\ ${ }^{1}$ Institut Pprime, UPR CNRS n ${ }^{0} 3346$, CNRS - Université de Poitiers - ENSMA, Physics and \\ Mechanics of Materials Department, ISAE-ENSMA, 1 avenue Clément Ader, BP 40109, 86961 \\ Futuroscope - Chasseneuil, France \\ ${ }^{2}$ Aircelle - SAFRAN group, Materials and Process Department, route du pont VIII, 76700 \\ Gonfreville-L'Orcher, France \\ ${ }^{3}$ Aircelle - SAFRAN group, Materials and Process Department, 50 rue Pierre Curie, 78379 \\ Plaisir, France \\ ${ }^{4}$ Turbomeca - SAFRAN group, Materials, Processes and Investigations Department, 64511 \\ Bordes Cedex, France \\ ${ }^{5}$ Snecma - SAFRAN group, Materials and Process Department, Site de Villaroche, Rond-Point \\ René Ravaud, 77550 Moissy-Cramayel, France
}

Keywords: thermal overaging, intermetallic precipitation, microhardness, tensile properties, LCF properties

\begin{abstract}
Alloy 625 is widely used for petrochemical, marine and aerospace applications owing to its outstanding corrosion and mechanical properties at high temperatures. However, this alloy is prone to complex microstructure evolutions above $500^{\circ} \mathrm{C}$ that may impact its mechanical properties. In this study, the impact of its microstructure evolutions occurring upon long-term thermal aging on its static and cyclic mechanical properties has been studied. Thermal exposures of up to $\sim 2000$ hours in the $550^{\circ} \mathrm{C}-900^{\circ} \mathrm{C}$ temperature range have been investigated. TTT diagrams of the $\delta$ and $\gamma^{\prime \prime}$ phases were established based on high resolution scanning electron microscopy observations. The evolutions of secondary carbides distributions were also followed. It has been observed a steep increase of the room temperature microhardness after overagings performed at $650^{\circ} \mathrm{C}$ and $700^{\circ} \mathrm{C}$ due to the precipitation of the $\gamma^{\prime \prime}$ phase. Moreover, it is also clearly evidenced a strengthening effect of the $\delta$ phase after long-term thermal exposures at temperatures in excess of $700^{\circ} \mathrm{C}$. Finally, the impact of a thermal aging in the $\gamma^{\prime \prime}$ precipitation domain on the high temperature tensile and low cycle fatigue properties was evaluated. It is shown a beneficial effect of the $\gamma^{\prime \prime}$ precipitation to the fatigue life and to the tensile properties up to $750^{\circ} \mathrm{C}$. It is also shown that the loss of high temperature ductility is not correlated to the precipitation of grain boundary secondary carbides. $\gamma^{\prime}$ precipitation and the $\gamma^{\prime} \rightarrow \delta$ transformation are also shown to be faster under cyclic loading compared to pure thermal aging.
\end{abstract}

\section{Introduction}

Inconel $^{\mathrm{TM}} 625$ is a nickel-based superalloy developed close to 60 years ago to achieve a good combination of mechanical strength, fracture toughness, fabricability, weldability and corrosion resistance under aggressive environments both at room and high temperatures [1,2]. This alloy 
is widely used in the petrochemical, marine, nuclear, power generation and aerospace industries [1-7]. In the aerospace industry, Alloy 625 is used as turbine shrouds, spray bars, hydraulic tubing, armoring and thrust reversers systems. This alloy is nowadays facing a renewed attention for the design and manufacturing of plugs for the exhaust parts in new generations of civil aeroengines due to the increase in operating temperatures, temperatures which will prevent original engine makers from using Ti-based alloys.

Since these aeroengines components are submitted to complex thermomechanical histories resulting from the very different operating conditions encountered during regular flights, the microstructure of Alloy 625 is very likely to evolve with possible consequences on the mechanical properties and on its in-service durability. Indeed, while Alloy 625 is a solid solution strengthened alloy in the as-heat treated state thanks to its high chromium and molybdenum contents [1], this alloy was proved in the past to be sensitive to the precipitation of strengthening intermetallic phases such as $\mathrm{Ni}_{2}(\mathrm{Cr}, \mathrm{Mo})$ of $\mathrm{Pt}_{2} \mathrm{Mo}$ structure $[5,6,8]$ or such as the $\mathrm{Ni}_{3} \mathrm{Nb}^{\prime}$ ' phase of $\mathrm{DO}_{22}$ structure due its non-negligible niobium content [3,5-10]. From the open literature, six main phases can be found in the austenitic $\gamma$ matrix after various types of thermal exposure $\left(\gamma^{\prime}\right.$, $\delta$ and $\mathrm{Ni}_{2}(\mathrm{Cr}, \mathrm{Mo})$ intermetallic phases, $\mathrm{M}_{6} \mathrm{C}$ and $\mathrm{M}_{23} \mathrm{C}_{6}$ secondary carbides, $\mathrm{MC}$ primary carbides) and over seven minor precipitations (rich $\alpha-\mathrm{Cr}$ particles, $\mu$ TCP particles, Laves particles, Si-rich particles ...) were identified to nucleate/decompose/transform upon thermal aging [1, 3, 5-16]. The interested reader is referred to a recent paper from the authors summarizing phases' evolutions in the $550^{\circ} \mathrm{C}-900^{\circ} \mathrm{C}$ temperature range and analyzing at the impact of the forming process on their precipitation kinetics [17].

These microstructure evolutions were found to greatly impact the room and high temperature mechanical properties such as hardness and tensile strength through the precipitation of $\gamma^{\prime}$ ' and $\mathrm{Ni}_{2}(\mathrm{Cr}, \mathrm{Mo})$ phases $[5,10,11,13,16,18,19]$ or toughness and ductility through the combined impacts of the precipitation of secondary carbides $\left(\mathrm{M}_{6} \mathrm{C}, \mathrm{M}_{23} \mathrm{C}_{6}\right)$ and of the $\mathrm{Ni}_{2}(\mathrm{Cr}, \mathrm{Mo})$ intermetallic phase or even TCP phases $[5,11,13,16,18,20]$. As an example, a spectacular increase (over a factor 2.5 ) of the $0.2 \%$ yield stress (YS) was observed after long thermal agings performed in the $500^{\circ} \mathrm{C}-650^{\circ} \mathrm{C}$ temperature range due to the $\gamma^{\prime}{ }^{\prime}+\mathrm{Ni}_{2}(\mathrm{Cr}, \mathrm{Mo})$ precipitation $[5,7$, $11,16]$. However, only few investigations were devoted to the impact of the thermal (over)aging on the high temperature (HT) mechanical properties $[7,11]$ and, to the authors' best knowledge, only one evaluated its impact on the high temperature fatigue properties [21].

Within this context, the aim of the present article is to investigate the impact of microstructure evolutions occurring in the $550^{\circ} \mathrm{C}-900^{\circ} \mathrm{C}$ temperature range on the room temperature (RT) microhardness. In addition, the impact of a thermal aging performed in the $\gamma$ ' precipitation domain on the tensile properties from RT up to $800^{\circ} \mathrm{C}$ and on the low cycle fatigue (LCF) properties will be analyzed.

\section{Material and experimental procedures}

Materials, thermal overagings and microstructure characterizations

In the present investigation, all samples were machined by EDM (Electron Discharge Machining) from an as-rolled + solution treated sheet by whose thickness is $0.8 \mathrm{~mm}$. This sheet was supplied by Haynes International in a mill-annealed state (mill annealing performed at a maximum temperature of $1038^{\circ} \mathrm{C}+/-4^{\circ} \mathrm{C}$ ). The chemical composition of the sheet is given in Table I. In this as-received state, the grain size excluding twin boundaries is $\sim 12.8 \mu \mathrm{m}$ (close to ASTM 10). The volume fraction and average size of secondary carbides were measured to be $0.77 \%$ and $0.32+/-0.11 \mu \mathrm{m}$ respectively in this as-received state [17]. Very few primary 
carbides were detected. The as-received sheet was found to be very weekly textured using EBSD characterizations (texture index 2.4) [17, 19].

Aging heat treatments under air were performed using four different furnaces and samples whose dimensions were $20 * 20 \mathrm{~mm}^{2}$. The aging temperature of the samples was controlled with a $+/$ $1{ }^{\circ} \mathrm{C}$ precision using a $\mathrm{K}$-type thermocouple positioned in the immediate vicinity of the samples. Heat treatments were performed in the $550^{\circ} \mathrm{C}-900^{\circ} \mathrm{C}$ temperature range and for durations up to $\sim 2000$ hours. Forty-six aging conditions were investigated. After each aging heat treatment, samples were air quenched. These samples used to analyze the microstructure evolutions as a function of the thermal exposure length and temperature were also used subsequently for RT microhardness characterizations.

To characterize the microstructure evolutions of Alloy 625 as a function of the thermal aging, samples were mechanically polished up to a mirror finish (final polishing using a $1 \mu \mathrm{m}$ diamond paste). A special care was taken to remove all the oxidized layers of the samples that had developed upon thermal aging. Samples were subsequently electrochemically polished using perchloric acid (10 pct. in volume) in methanol. This preparation allows both the characterization of the grain structure of the alloy and of different classes of precipitates (MC primary carbides, $\mathrm{M}_{6} \mathrm{C}$ and $\mathrm{M}_{23} \mathrm{C}_{6}$ secondary carbides, $\gamma$ '" phase and $\delta$ phase).

Particles observations were performed using a JEOL JSM ${ }^{\mathrm{TM}}$ 7000F Field Emission Gun SEM using secondary (SEI) and backscattered (BSE) electron imaging modes. Observations were performed using both low magnifications (below a 5000 times magnification) in BSE mode for the carbides characterization while $\delta$ and $\gamma^{\prime \prime}$ phases were characterized using the SEI mode. Observations were performed using an acceleration voltage of $25 \mathrm{kV}$.

Table I. Chemical composition of the studied Alloy 625 (weight pct)

\begin{tabular}{ccccccccccccc}
\hline $\mathrm{Ni}$ & $\mathrm{Cr}$ & $\mathrm{Mo}$ & $\mathrm{Fe}$ & $\mathrm{Nb}$ & $\mathrm{Mn}$ & $\mathrm{Al}$ & $\mathrm{Si}$ & $\mathrm{Ti}$ & $\mathrm{C}$ & $\mathrm{Ta}$ & $\mathrm{P}$ & $\mathrm{S}$ \\
\hline Base & 21.28 & 8.7 & 3.83 & 3.58 & 0.27 & 0.26 & 0.30 & 0.28 & 0.029 & 0.007 & $<0.005$ & $<0.002$ \\
\hline
\end{tabular}

Microhardness characterizations

Microhardness characterizations were performed at RT using the heat treated coupons after they had been polished up to a mirror finish (i.e. without any chemical etching or electrochemical polishing). They were performed using a Fisher HM T3 instrumented Vickers microindentor where both the evolution of the applied force and penetration depth can be continuously followed during each indentation. Experiments were performed according to the following procedure: 1) loading in 15 seconds up to a $300 \mathrm{mN}$ applied force; 2) a 3 seconds dwell at maximum load; 3) unloading in 15 seconds. For each sample, arrays of 49 indentations at least were performed. A minimum distance of $57 \mu \mathrm{m}$ between each individual indentation was used to avoid any influence of the neighboring indentations on the locally measured hardness. For each microstructural state, an arithmetic average of all these 49 indentations (at least) will be provided, and the error bars for each experimental point will correspond to $+/-$ the standard deviation. It has to be noted that indentations performed in primary carbides have been removed from the statistics (less than one indentation per sample). In the softest state (i.e. the as-received state), the penetration depth was $\sim 2 \mu \mathrm{m}$. Hence, using such a load with such a grain size (grain size of $\sim 12-13 \mu \mathrm{m}$ ), microhardness measurements employed here are mainly sensitive to the intragranular precipitation and, to a lesser degree, to the grain size. 


\section{$\underline{\text { High temperature tensile tests }}$}

Tensile tests were performed using flat samples whose gage length and gage section are $15 \mathrm{~mm}$ and $4^{*} 0.8 \mathrm{~mm}^{2}$ respectively. The total length of the sample was $62 \mathrm{~mm}$. Samples were machined with the gage length aligned along the rolling direction of the sheet. Before any tensile test, each faces and edges of the samples were carefully polished up to a $4000 \mathrm{SiC}$ grade and the sections were carefully measured using a profilometer.

Tensile tests were performed at RT, $200^{\circ} \mathrm{C}, 350^{\circ} \mathrm{C}, 550^{\circ} \mathrm{C}, 650^{\circ} \mathrm{C}, 700^{\circ} \mathrm{C}, 750^{\circ} \mathrm{C}$ and $800^{\circ} \mathrm{C}$. They were performed using an Instron 8562 electromechanic machine equipped with a high temperature contact extensometer. Heating was ensured with a two-zone resistive furnace. The following tensile testing procedure was used: heating at $20^{\circ} \mathrm{C} \cdot \mathrm{min}^{-1}$ followed by a 30 minutes soak time before starting the tensile test at a constant displacement rate of $15.10^{-3} \mathrm{~mm} \cdot \mathrm{s}^{-1}$ up to failure (a strain rate nearly $10^{-3} \mathrm{~s}^{-1}$ at the beginning of the test). The cooling down to RT after samples' failure was also performed at $20^{\circ} \mathrm{C} \cdot \mathrm{min}^{-1}$. These tensile tests were performed on both the as-received sheet and after one part of this sheet had been exposed to a 500 hours prior aging at $650^{\circ} \mathrm{C}$.

\section{High temperature fatigue tests}

Fatigue experiments were performed at $650^{\circ} \mathrm{C}$ and $750^{\circ} \mathrm{C}$ using samples machined from the asmilled annealed sheet or from the prior aged one for 500 hours at $650^{\circ} \mathrm{C}$ (same sheet as for tensile experiments). Fatigue samples have exactly the same geometry as for tensile tests and they were also machined with the gage length along the rolling direction of the sheet. The faces and edges of the samples' gage length were carefully polished up to a $1 \mu \mathrm{m}$ mirror finish a care was taken for the bearing section measurements.

Due to the flat geometry of the samples, fatigue tests were performed under load-controlled conditions, with a positive stress ratio $\mathrm{R}_{\sigma}=0.05$. They were performed at a frequency $\mathrm{f}=0.116$ $\mathrm{Hz}$ at $650^{\circ} \mathrm{C}$, using the same machine as for tensile tests. This frequency was chosen to achieve an almost similar strain rate as for tensile experiments. Extensometric measurements were performed during all these fatigue tests to characterize the cyclic behavior. Two additional fatigue tests performed at $650^{\circ} \mathrm{C} / \mathrm{R}_{\sigma}=0.05 / \mathrm{f}=0.116 \mathrm{~Hz}$ without any prior aging and under a maximum applied stress $\sigma_{\max }=400 \mathrm{MPa}$ were interrupted after 400 and 71630 cycles. These two tests were then continued by a tension test at $650^{\circ} \mathrm{C}$ with a constant displacement rate of $15.10^{-3} \mathrm{~mm} . \mathrm{s}^{-1}$ up to failure. These tests were aimed at characterizing the residual tensile behavior after cyclic solicitation.

Further experiments were also performed at $650^{\circ} \mathrm{C}$ and $750^{\circ} \mathrm{C}$ using $10 \mathrm{~Hz}$ and $50 \mathrm{~Hz}$ frequencies, without any cyclic behavior characterization (i.e. no extensometric measurement).

\section{Experimental results and discussion}

\section{Impact of thermal overaging on microstructure and RT microhardness evolutions}

Fig. 1 shows four examples of intermetallic precipitation in alloy 625 after thermal exposures for 2000 hours at $550^{\circ} \mathrm{C}$ (Fig. 1a), at $650^{\circ} \mathrm{C}$ (Fig. 1b), at $750^{\circ} \mathrm{C}$ (Fig. 1c) and at $800^{\circ} \mathrm{C}$ (Fig. 1d). A more exhaustive microstructure characterization has already been performed recently by $\mathrm{L}$. Mataveli Suave et al. [17]. These microstructure states have been especially chosen in the present 
article to illustrate the main type of microstructure evolutions that may control the subsequent mechanical upon thermal exposure. It is observed in Figs. 1a and 1b the precipitation of intragranular $\mathrm{Ni}_{3} \mathrm{Nb} \gamma$ ' particles. This precipitation is very small at $550^{\circ} \mathrm{C}$ (see white arrow in Fig. 1a) and quasi spherical. At $650^{\circ} \mathrm{C}, \gamma$ ' particles exhibit a classical ellipsoidal morphology (Fig. 1b). $\gamma$ ' particles were also observed to grow during increased exposure time at this temperature. The coarsening process of $\gamma$ ' particles in Alloy 625 was observed to follow the Lifshitz-Slyozov-Wagner (LSW) theory once a lens morphology of the precipitate is reached. An apparent activation energy of $358 \mathrm{~kJ}^{-\mathrm{mol}^{-1}}$ for this coarsening process has been determined previously [17]. At $750^{\circ} \mathrm{C}$, both $\gamma^{\prime}$ and $\delta$ precipitations are observed for short exposures, typically below $\sim 1000$ hours. However, it is observed in Fig. 1c only the intragranular precipitation of $\delta$ needles without any remaining coarse $\gamma$ ' particles. After thermal exposures at $800^{\circ} \mathrm{C}$, the sole intragranular $\delta$ precipitation has been observed, without any $\gamma^{\prime}$ particles, even after short exposures. $\delta$ platelets have been observed to extend throughout all the grain for thermal exposures longer than 100 hours at this temperature (see e.g. Fig. 1d). In addition, both intergranular and intragranular precipitation of $\mathrm{M}_{23} \mathrm{C}_{6}$ and $\mathrm{M}_{6} \mathrm{C}$ carbides was observed at $750^{\circ} \mathrm{C}$ and $800^{\circ} \mathrm{C}$ (see e.g. white grain boundaries particles in Figs. 1c and 1d).
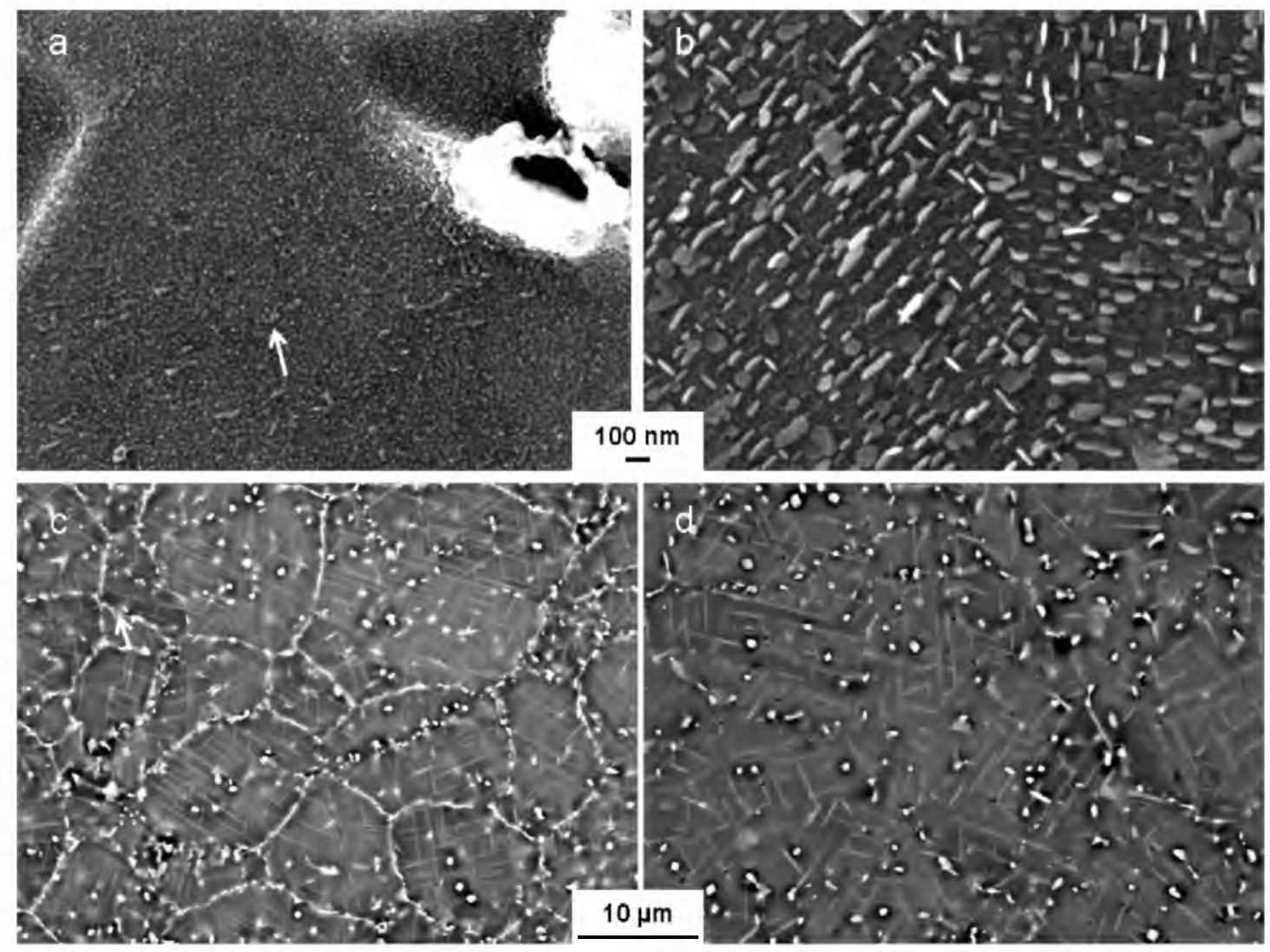

Figure 1. Microstructures observed after thermal exposures of 2000 hours at $550^{\circ} \mathrm{C} \mathrm{(a),} \mathrm{at} 650^{\circ} \mathrm{C}$ (b), at $750^{\circ} \mathrm{C}$ (c) and at $800^{\circ} \mathrm{C}$ (d). Note the precipitation of $\gamma^{\prime}$ 'particles in (a) and (b) (see arrow in a) and the intragranular $\delta$ platelets extending throughout all the grain in (c) and (d).

The TTT diagram for the $\delta$ and the $\gamma$ " precipitation established from high resolution SEM observations of all the investigated thermal exposures is presented in Fig. 2. The $\delta$ phase is observed to precipitate in the $650^{\circ} \mathrm{C}-900^{\circ} \mathrm{C}$ temperature domain and preferentially between 
$700^{\circ} \mathrm{C}$ and $800^{\circ} \mathrm{C}$, while the $\gamma$ ' phase was found to precipitate in the $550^{\circ} \mathrm{C}-750^{\circ} \mathrm{C}$ temperature domain, with a preferential formation at $650^{\circ} \mathrm{C}$ and $700^{\circ} \mathrm{C}$. These precipitation domains are in quite good agreement with data extracted from the open literature [2, 11, 12, 14]. Some differences in the $\delta$ precipitation nose were however noted between the present study and other studies, see e.g. [22].

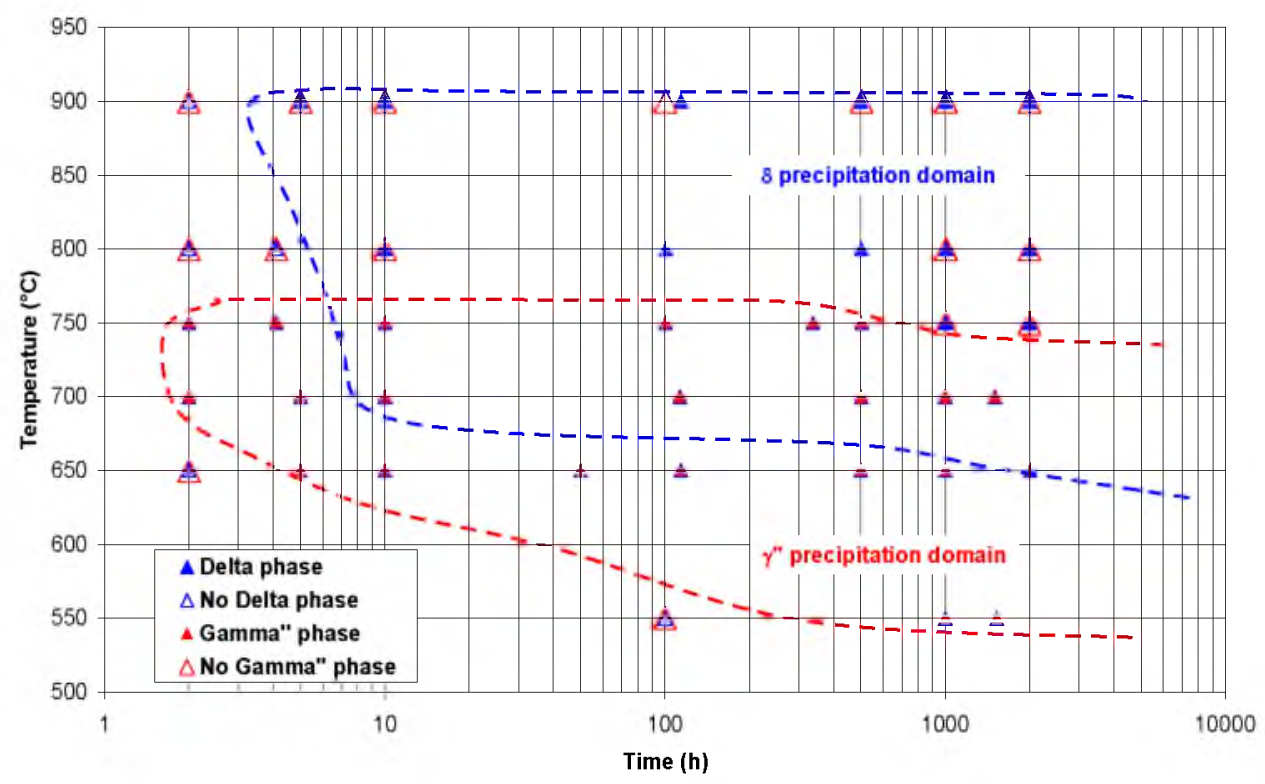

Figure 2. TTT diagram of the $\gamma$ ' and $\delta$ phases in the studied Alloy 625

The evolution of RT microhardness is shown in Fig. 3. The initial RT hardness without any thermal exposure is $\mathrm{Hv}=331+/-2$. It is observed a hardness increase for all aging temperatures, except at $900^{\circ} \mathrm{C}$ where the RT hardness remains almost stable, with a possible final increase due to the $\delta$ particle growth. At lower temperatures, a continuous increase in Vickers hardness is observed up to 1000 hours of thermal exposure, whatever the temperature. At the lowest temperature $\left(550^{\circ} \mathrm{C}\right)$, this hardness progressive and continuous increase is correlated to the precipitation of $\mathrm{Ni}_{2}(\mathrm{Cr}, \mathrm{Mo})$ particles $[5,6,8]$ and to the $\gamma$ ' precipitation over 1000 hours [17]. At $650^{\circ} \mathrm{C}$, a sluggish increase in hardness is observed for the first 5 hours. This increase was observed already after 30 minutes despite no $\gamma$ ' particles could have been observed using high resolution SEM observations (Fig. 2). After 5 hours, a steep increase in hardness correlated to the $\gamma$ ' precipitation is observed. One can also observe that the highest RT hardnesses are obtained after $650^{\circ} \mathrm{C}$ thermal exposures, i.e. at a temperature where only the $\gamma^{\prime}$ ' phase can be encountered (Fig. 2). Microhardness is indeed peaking after a 1000 hours thermal exposure at $650^{\circ} \mathrm{C}$ and a subsequent small decrease is observed when increasing the exposure up to 2000 hours. This small decrease has been correlated to the onset of the $\gamma$ ' $\rightarrow \delta$ transformation occurring at this temperature for very long exposures. This transformation is illustrated in the micrograph shown in Fig. 3 where first evidences of $\delta$ formation are highlighted by white arrows.

Thermal exposures at $700^{\circ} \mathrm{C}$ and $750^{\circ} \mathrm{C}$ lead to a continuous increase of the RT microhardness due to first the $\gamma$ ' precipitation simultaneously to the $\delta$ one (see Fig. 2), and then to the growth of the $\delta$ particles within the grains. The hardness evolution also follows a similar trend up to 100 hours of exposure at $800^{\circ} \mathrm{C}$, and then a stabilization (or even a small decrease) is observed. 
From these RT microhardness characterizations, it is clearly demonstrated that thermal exposures in the $550^{\circ} \mathrm{C}-800^{\circ} \mathrm{C}$ temperature range lead to an improvement of the static properties. The most significant strengthening within the investigated conditions results from the $\gamma$ " precipitation at $650^{\circ} \mathrm{C}$. However, it is also clearly observed here, and probably for the first time, a strengthening provided by the $\delta$ precipitation. Such a strengthening was only supposed in a previous study using Alloy 625 [5].

In our opinion, this strengthening may result from a "composite strengthening" since $\delta$ particles are extending throughout all the grain in this small grain Alloy 625 [23]. We would expect a different impact of the $\delta$ precipitation on Alloy 625 hardness with a coarser grain size. From the present characterizations, it is also observed that RT microhardness is a useful tool to probe microstructure evolutions in addition to conventional microstructure observations using SEM and/or TEM.

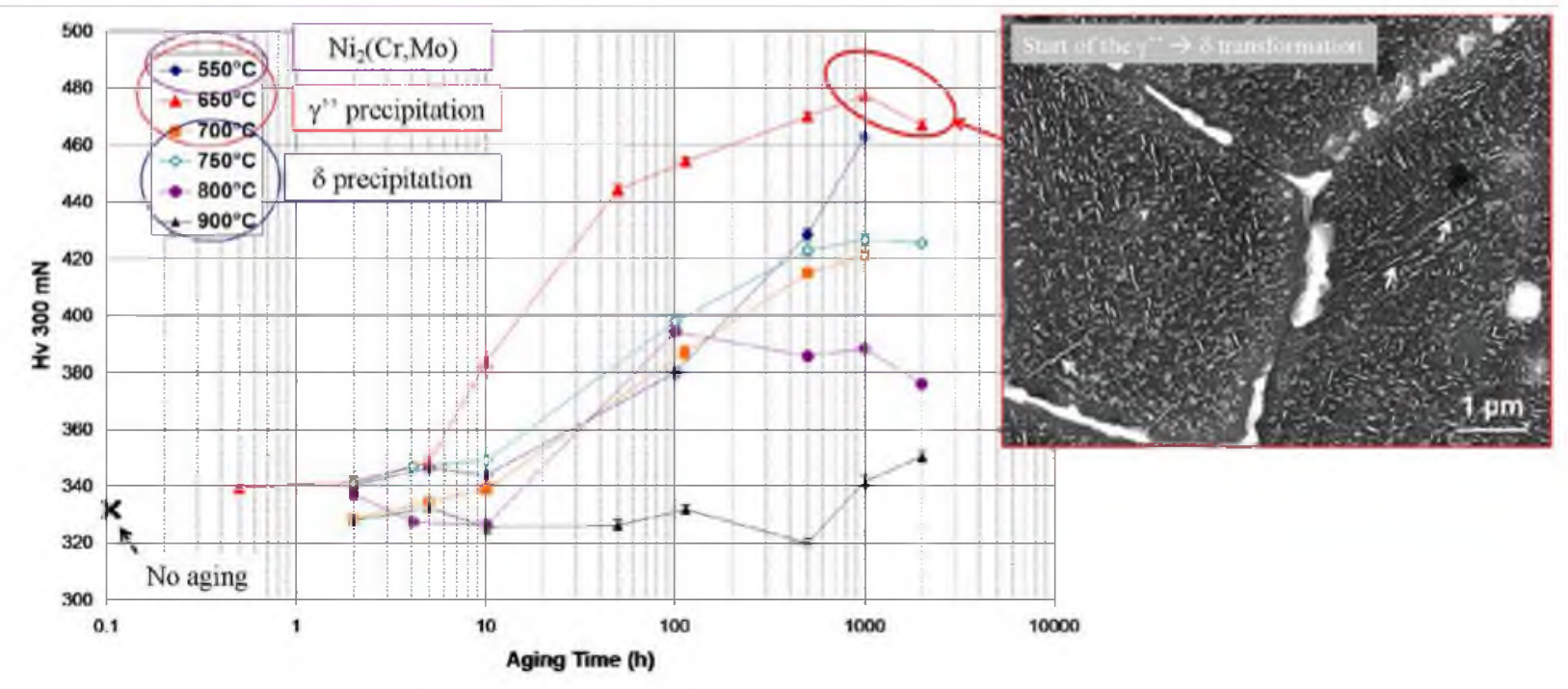

Figure 3. Evolution of the RT microhardness after long-term thermal exposure in the $550^{\circ} \mathrm{C}$ $900^{\circ} \mathrm{C}$ temperature range and illustration of the impact of the $\gamma^{\prime \prime} \rightarrow \delta$ transformation at $650^{\circ} \mathrm{C}$.

Impact of a thermal aging at $650^{\circ} \mathrm{C}$ on the high temperature tensile properties

Based on the previous RT hardness measurements, it has been chosen to investigate the impact of an aging heat treatment performed at $650^{\circ} \mathrm{C}$ on the high temperature tensile properties. A thermal exposure of 500 hours was chosen based on Fig. 3 since it produces nearly the highest RT hardness with reasonable thermal exposure duration. Compared to the as-received alloy, which is only solid solution strengthened, such a thermal exposure before tension tests leads to the precipitation of $\gamma$ " particles (see insert in Fig. $4 \mathrm{~b}$ ) whose length is $\sim 42.5 \mathrm{~nm}$ [17]. In addition, the volume fraction of secondary carbides (mainly $\mathrm{M}_{23} \mathrm{C}_{6}$ ) raised from $0.77 \%$ up to $\sim 4 \%$. As observed in Fig. 4, these secondary carbides mainly nucleate at grain boundaries.

The impact of this prior aging heat treatment at $650^{\circ} \mathrm{C}$ on the tensile properties at $\mathrm{RT}, 650^{\circ} \mathrm{C}$ and $800^{\circ} \mathrm{C}$ is shown in Fig. 5. It is observed much higher yield and ultimate tensile stresses at RT and at $650^{\circ} \mathrm{C}$ after this prior thermal exposure. These better YS and UTS are accompanied by a decrease of the strain to failure at these two temperatures. One of the remarkable results is obtained comparing tensile properties at $800^{\circ} \mathrm{C}$ where no difference can be observed between both states, neither in ductility, nor in YS or UTS. It is also noted that the as-received alloy exhibit a serrated tensile behavior (the so-called Portevin - Le Chatelier effect) from $200^{\circ} \mathrm{C}$ up to 
$800^{\circ} \mathrm{C}$ with this strain rate. These serrations are not observed after a prior heat treatment in the $\gamma$ ' domain has been performed, except at $800^{\circ} \mathrm{C}$ in the very early stages of plastic deformation (i.e. up to $4-5 \%$ of total strain, see Fig. 5).

The impact of the prior aging heat treatment at $650^{\circ} \mathrm{C}$ on the YS, UTS and ductility evolutions as a function of the temperature is shown in Figs. 6. The YS is here measured at a $0.2 \%$ plastic deformation. It is observed that the YS and UTS are always higher for the alloy submitted to this specific prior thermal exposure (Fig. 6a). A YS difference of up to a factor of $\sim 2$ is observed in the $200^{\circ} \mathrm{C}-650^{\circ} \mathrm{C}$ temperature range. Above $650^{\circ} \mathrm{C}$, the difference in YS between these two microstructural states is progressively decreasing up to almost no difference at $800^{\circ} \mathrm{C}$, as already observed in Fig. 5. The reason for the steeper decrease in YS and UTS for the overaged samples results from the progressive dissolution of the $\gamma$ ' particles above $700^{\circ} \mathrm{C}$ and their transformation into $\delta$ particles (see TTT diagram in Fig. 2). A complete dissolution of $\gamma^{\prime}$ particles is even obtained at $800^{\circ} \mathrm{C}$ (see Fig. 2). Indeed, as already observed in Fig. 3, microhardness is much more lower at $700^{\circ} \mathrm{C}, 750^{\circ} \mathrm{C}$ and $800^{\circ} \mathrm{C}$ compared to its values at $650^{\circ} \mathrm{C}$.

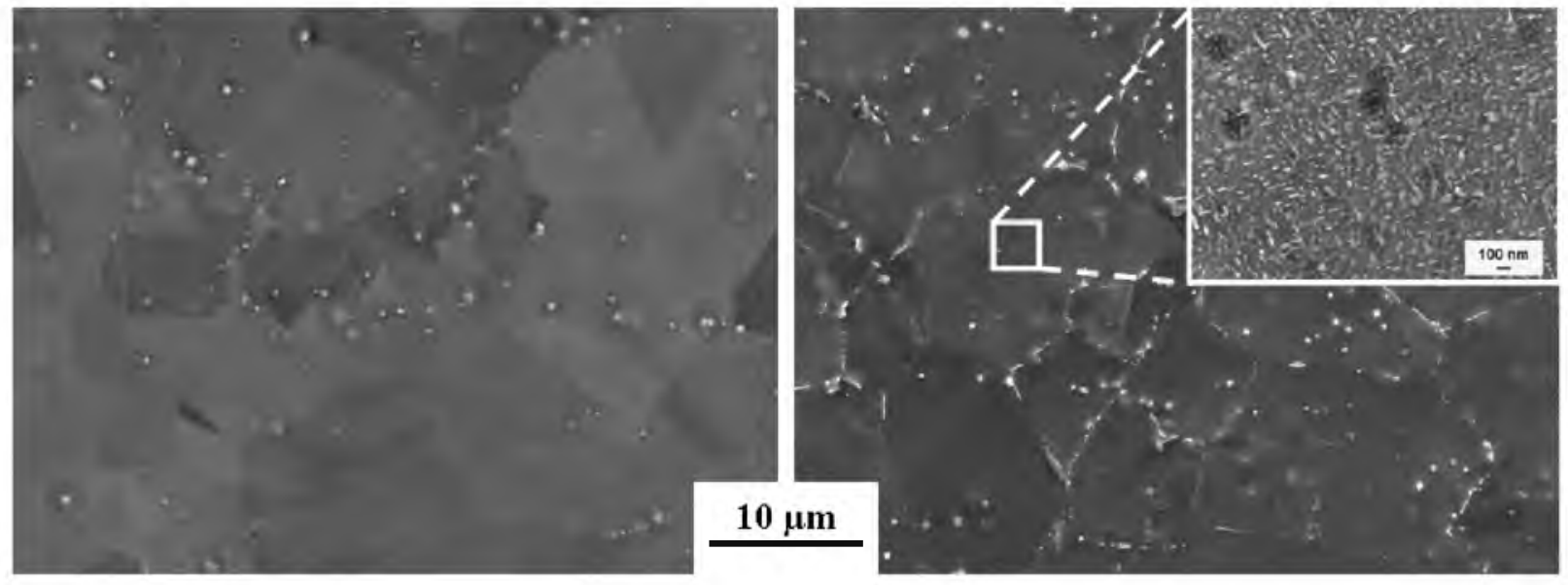

Figure 4. Secondary carbides precipitation in the as-received state (a) and after $500 \mathrm{~h}$ at $650^{\circ} \mathrm{C}$ (b). The intragranular $\gamma^{\prime}$ 'precipitation after $500 \mathrm{~h}$ at $650^{\circ} \mathrm{C}$ is shown in the insert in (b).

The ductility follows the inverse trend compared to YS and UTS ones (Fig. 6b): its value is always higher without any prior thermal exposure. The observed very high ductility at $650^{\circ} \mathrm{C}$ in the as-received state remains to be explained and will not be further commented upon. As for YS and UTS, no more difference in ductility is observed during tensile tests at $800^{\circ} \mathrm{C}$. This last result, in addition to no difference in YS and UTS at $800^{\circ} \mathrm{C}$, clearly indicates that the high temperature tensile properties of Alloy 625 are not controlled by the grain boundary secondary carbides precipitation. Indeed, no dissolution of secondary carbides occurs at $800^{\circ} \mathrm{C}$ and the additional exposure at this temperature during the tensile test would instead favour an increase in secondary carbide content [17]. Hence, contrary to what has been believed in previous studies $[10,20,24]$, the decrease in ductility after thermal exposures in the $600^{\circ} \mathrm{C}-750^{\circ} \mathrm{C}$ temperature range does not result from a secondary carbide grain boundary precipitation, but rather from the intragranular precipitation of the $\gamma$ ' phase. This result is in rather good agreement with the ones proposed by Kölher [18]. One additional analysis that can be drawn from the present study is that a thermal exposure of $\sim 30$ minutes (the soak time before the tensile test) is enough to erase all the consequences of a 500 hours thermal exposure at $650^{\circ} \mathrm{C}$ from a high-temperature-tensileproperties point of view. 


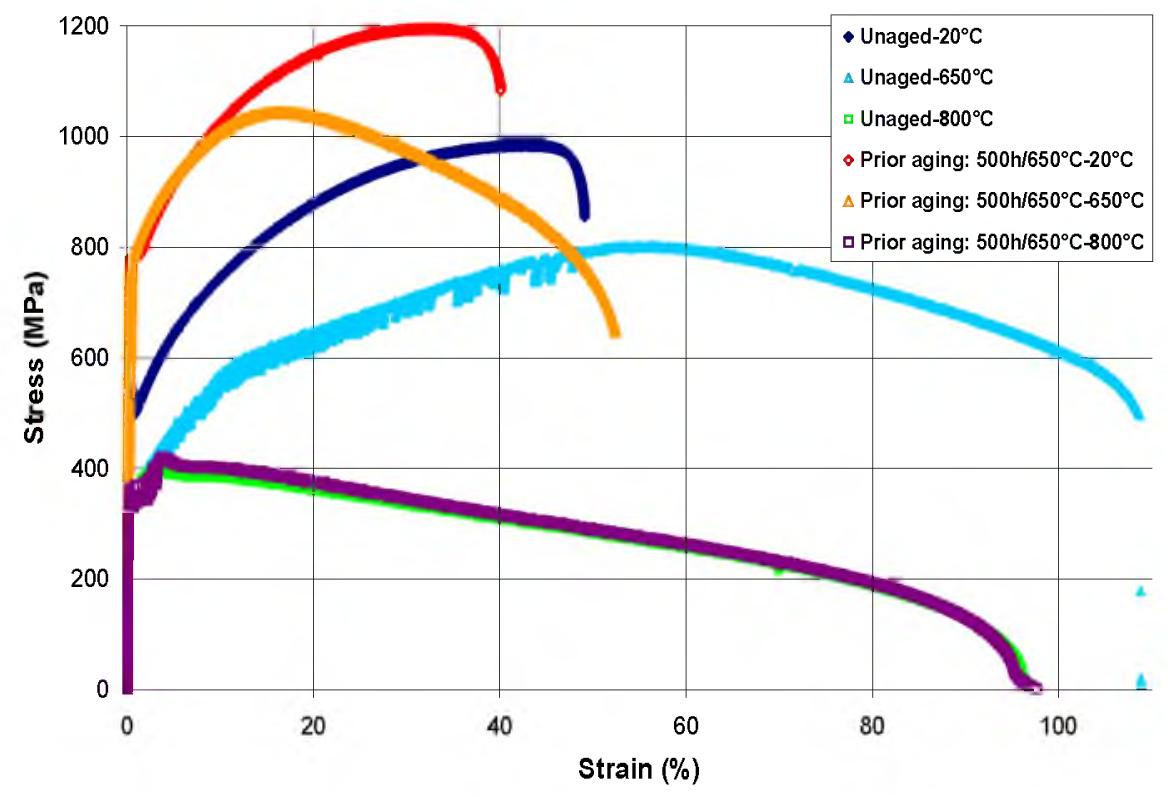

Figure 5. Tensile behavior at RT, $650^{\circ} \mathrm{C}$ and $800^{\circ} \mathrm{C}$ in the as-received state and after a $500 \mathrm{~h}$ thermal exposure at $650^{\circ} \mathrm{C}$.
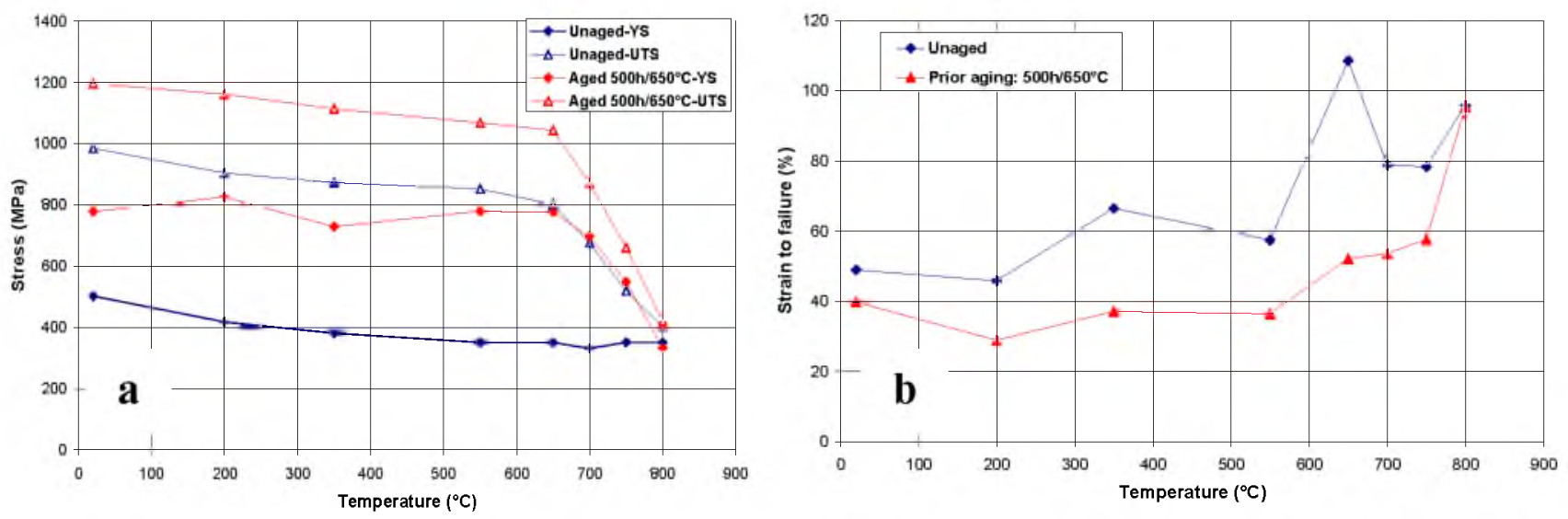

Figure 6. Impact of a prior aging of 500 hours at $650^{\circ} \mathrm{C}$ on the YS (defined at a $0.2 \%$ plastic strain) and UTS (a) and on the ductility (b) evolutions as a function of temperature.

Impact of a thermal aging at $650^{\circ} \mathrm{C}$ on the high temperature LCF properties and microstructure evolutions during LCF solicitation

The impact of the 500 hours thermal aging at $650^{\circ} \mathrm{C}$ on the LCF properties is shown in Fig. 7. It is observed a better LCF resistance at $650^{\circ} \mathrm{C}$ after the prior aging at $650^{\circ} \mathrm{C}$ had been performed. These better LCF properties can only be quantified in term of stress benefit $(+320 \mathrm{MPa})$ in Fig. 7 since LCF tests with reduced maximum applied stresses using the aged alloy always led to failures outside of the gage length of the samples. Keeping in mind that the $\mathrm{YS}$ at $650^{\circ} \mathrm{C}$ under the same strain rate conditions is $350 \mathrm{MPa}$ in the as-received state and $770 \mathrm{MPa}$ after the $500 \mathrm{~h} / 650^{\circ} \mathrm{C}$ thermal exposure (Figs. 5 and 6 ), it is here shown that the difference in LCF properties mainly results from a much higher YS after a prior aging had been performed in the 
$\gamma$ ' precipitation domain. Under such conditions of high mean applied stresses, the fatigue behavior of Alloy 625 in both states is characterized by a cyclic ratcheting (not shown here). This cyclic ratcheting has a lower magnitude during each cycle in the first hundred cycles and is then slower after the prior aging at $650^{\circ} \mathrm{C}$ compared to the as-received state. This is due to the strengthening provided by the $\gamma$ " precipitation, which limits the creep deformation of the alloy at this temperature. Fractographic observations (not shown) of all the samples tested at $650^{\circ} \mathrm{C} / \mathrm{f}=$ $0.116 \mathrm{~Hz}$ revealed a ductile failure with multiple surface initiation sites for fatigue lives below $\sim 10000$ cycles, whatever their initial microstructural state. Surface crack initiation on a primary carbide followed by an area of stable crack propagation was only observed for the longest fatigue test performed on the unaged alloy $\left(\sigma_{\max }=600 \mathrm{MPa}\right.$, fatigue life $=474658$ cycles $)$.

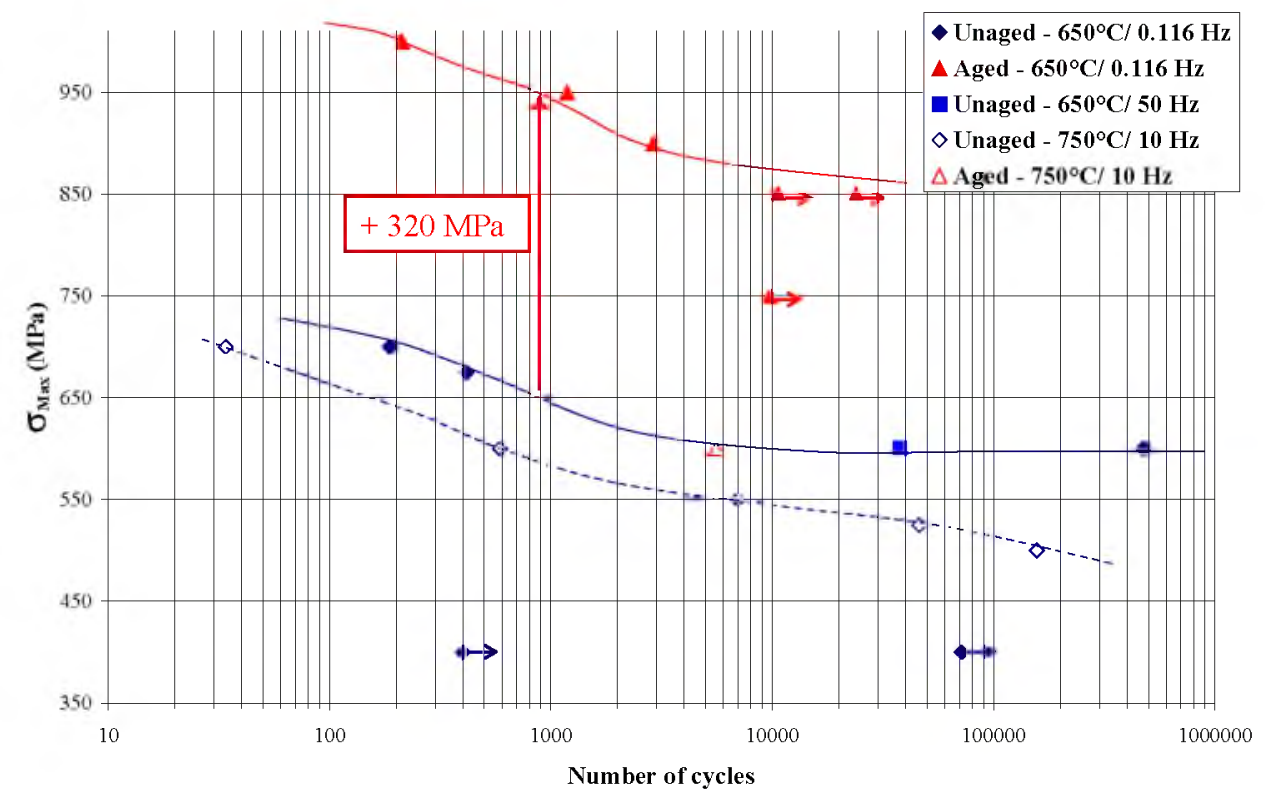

Figure 7. Impact of a 500 hours prior aging at $650^{\circ} \mathrm{C}$ on the load-controlled LCF properties of Alloy 625 at $650^{\circ} \mathrm{C}$ and $750^{\circ} \mathrm{C}$ with $\mathrm{R}_{\sigma}=0.05$.

A better fatigue life at $750^{\circ} \mathrm{C}$ after aging at $650^{\circ} \mathrm{C}$ is also observed in Fig. 7 , although only one result with fatigue failure within the gage length was obtained after this prior aging had been performed. These tests were performed at a much higher frequency $(10 \mathrm{~Hz})$ to limit the duration of the tests and the possible microstructure evolutions (typically, the $\gamma$ ' $\rightarrow \delta$ transformation at $750^{\circ} \mathrm{C}$ ) likely to occur during fatigue experiments at $750^{\circ} \mathrm{C}$ performed with a reduced frequency such as the one used for nearly all fatigue experiments at $650^{\circ} \mathrm{C}(\mathrm{f}=0.116 \mathrm{~Hz})$.

To characterize such microstructure evolutions likely to occur for the as-received alloy during fatigue tests at $650^{\circ} \mathrm{C} / \mathrm{f}=0.116 \mathrm{~Hz}$, two tests with $\sigma_{\max }=400 \mathrm{MPa}$ were interrupted after 400 and 71630 cycles respectively (the two unfailed specimens at the lower $\sigma_{\max }$ in Fig. 7). They were followed by tensile tests at $650^{\circ} \mathrm{C}$ up to failure with the same experimental conditions as the ones presented in the previous section. Figure 8 compares the tensile behaviors after such cyclic aging with the tensile behavior of Alloy 625 at this temperature with and without the $500 \mathrm{~h} / 650^{\circ} \mathrm{C}$ aging. It is clearly observed that after 400 cycles (i.e. 1.7 hours at $650^{\circ} \mathrm{C}$ ), the subsequent tensile behavior is nearly the same as without any aging, with almost the same strain to failure and the same UTS (compare the two blue curves in Fig. 8). It is also still observed serrations on the tensile curve after this cyclic aging that are typical of the tensile behavior of a solid solution strengthened Alloy 625. However, after 71630 cycles, the tensile behavior is almost identical to the result after a $500 \mathrm{~h}$ pure thermal aging at $650^{\circ} \mathrm{C}$ had been performed before 
the tension test. This is direct evidence that the mechanical properties are changing in the course of fatigue tests at $650^{\circ} \mathrm{C}$ due to microstructure evolutions. One should also notice that this prior cyclic aging of 71630 cycles lasted 178.15 hours. Since this cyclic aging leads to HT static properties nearly the same as after $500 \mathrm{~h}$ at $650^{\circ} \mathrm{C}$, this is a first indication that the $\gamma^{\prime}$ ' precipitation observed in Fig. 9a is faster during cyclic loading than under pure thermal aging. In addition, the $\gamma^{\prime} \rightarrow \delta$ transformation is also accelerated under cyclic solicitation, as observed in Fig. 9. Indeed, after these 71630 cycles at $650^{\circ} \mathrm{C}$, it was even observed first evidences of $\delta$ particles (see elongated filaments in Fig. 9a). This is much faster than under pure thermal exposure where this transformation was found to occur above 1000 hours (see Fig. 3 and our previous paper [17]). After 474658 cycles at $\sigma_{\max }=600 \mathrm{MPa} / 650^{\circ} \mathrm{C} / \mathrm{f}=0.116 \mathrm{~Hz}$, that is to say, 1138 hours of HT fatigue testing, some grains are observed to be fully lamellar $\delta$ (Fig. 9c). Compared to the microstructure observed after 2000 hours of thermal exposure at $650^{\circ} \mathrm{C}$ (Fig. $1 \mathrm{~b}$ and insert in Fig. 3), this is another direct evidence that the $\gamma$ ' $\rightarrow \delta$ transformation is faster under cyclic deformation. It is also noted remaining coarsened $\gamma$ ' particles between these $\delta$ platelets (see arrow in Fig. 9b).

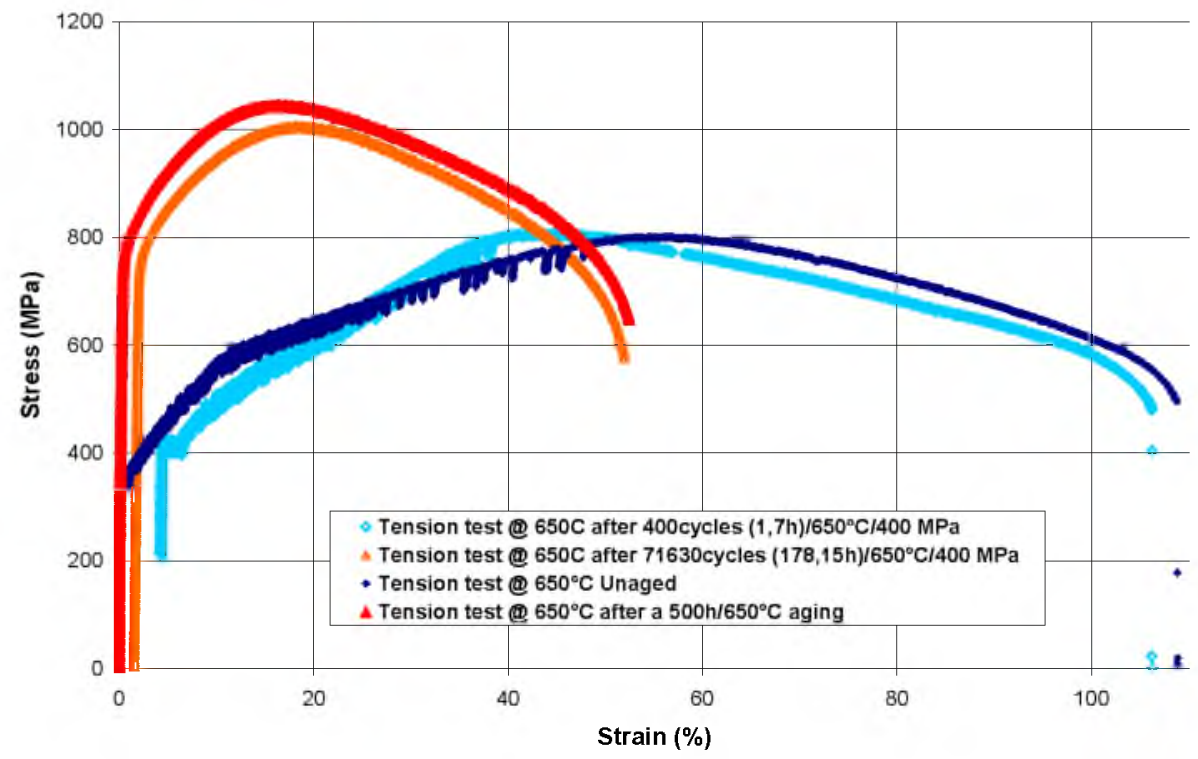

Figure 8. Residual tensile behavior at $650^{\circ} \mathrm{C}$ after 400 and 71630 fatigue cycles at $650^{\circ} \mathrm{C} / \mathrm{R}_{\sigma}=$ $0.05 / \mathrm{f}=0.116 \mathrm{~Hz}$ had been performed. These tests are compared to the tensile behavior of Alloy 625 with a prior thermal aging of 500 hours at $650^{\circ} \mathrm{C}$ or without any prior thermal exposure.

One may also notice in Fig. 9c that two grains are fully lamellar while other ones are only populated with $\gamma$ ' particles. This suggests that the $\gamma$ ' $\rightarrow \delta$ transformation is sensitive to the local grain orientation and hence to the local plastic activity. In fact, it was already shown in the past that the $\delta$ precipitation is highly sensitive to the plastic deformation in Inconel 718 [25] and that residual plastic deformation inherited from the forming process of Alloy 625 accelerates the $\delta$ precipitation [17]. This process probably results from more numerous nucleation sites for $\gamma$ ' and $\delta$ particles, as well as faster diffusion under stress compared to under pure thermal exposure.

From the present characterizations, it is clearly evidenced a need to deeply investigate the impact of the loading frequency on the fatigue life of Alloy 625 since the cyclic behavior will be greatly dependent on the microstructure evolutions that are likely occur, microstructures evolutions which are also dependent on the cyclic deformation. Indeed, a cyclic hardening is occurring in 
the course of HT mechanical cycling between $550^{\circ} \mathrm{C}$ and $700^{\circ} \mathrm{C}$ mainly due to the precipitation of the $\gamma^{\prime}$ phase, and to a lesser extent to the deformation substructures established during cycling. In addition, the impact of the $\delta$ precipitation on the fatigue properties would require deeper investigations since it has been shown a beneficial effect of this phase to the RT static properties (Fig. 3). Finally, in an aim to achieve a good predictivity of the HT fatigue life of Alloy 625 , a microstructure-sensitive modeling taking into account the under-loading precipitation kinetics of $\gamma^{\prime \prime}$ and $\delta$ phases, as well as their transformations and dissolution would be necessary. All these points are currently under investigation.
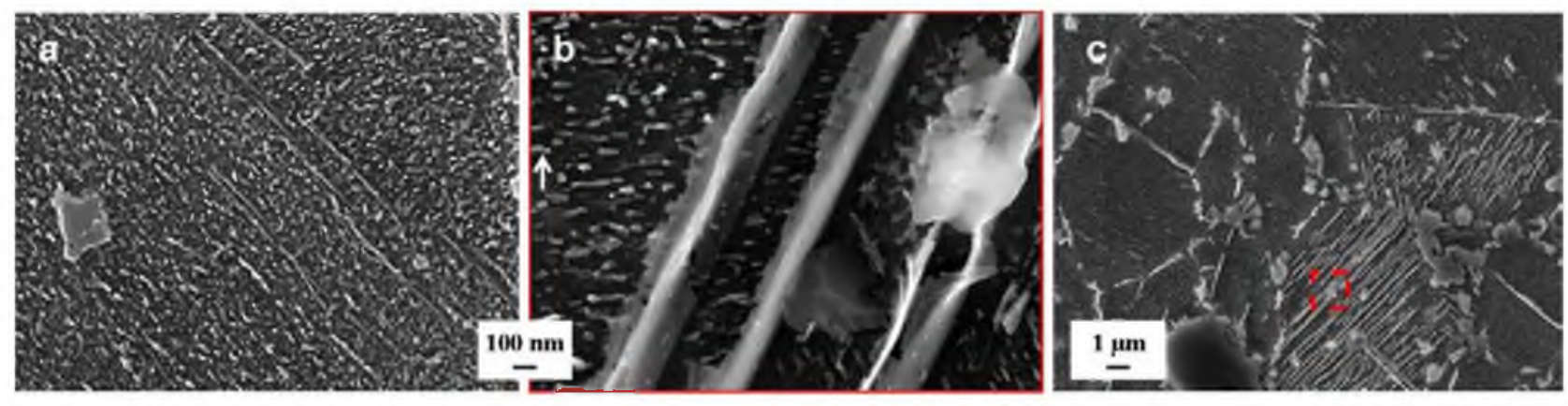

Figure 9. Microstructure observed after 71630 cycles at $\sigma_{\max }=400 \mathrm{MPa} / 650^{\circ} \mathrm{C} / \mathrm{f}=0.116 \mathrm{~Hz}$ and a subsequent tensile test at $650^{\circ} \mathrm{C} /$ loading rate $=15.10^{-3} \mathrm{~mm} \cdot \mathrm{s}^{-1}$ (a) and after $474658 \mathrm{cycles}$ at $\sigma_{\max }=600 \mathrm{MPa} / 650^{\circ} \mathrm{C} / \mathrm{f}=0.116 \mathrm{~Hz}(\mathrm{~b}, \mathrm{c})$. Note that (b) is a magnification of the red dotted area in (c) and that the white arrow in (b) points out at $\gamma$ ' particles.

\section{Conclusions}

The impact of thermal exposures on the static and cyclic mechanical properties of Alloy 625 has been studied. The evolution of the RT microhardness has been investigated after thermal exposures between $550^{\circ} \mathrm{C}$ and $900^{\circ} \mathrm{C}$ for up to $\sim 2000$ hours. In addition, the impact of a 500 hours thermal aging at $650^{\circ} \mathrm{C}$ on the HT tensile and LCF properties has been investigated.

As a first main conclusion, thermal exposures in the $550^{\circ} \mathrm{C}-800^{\circ} \mathrm{C}$ temperature increase the RT static mechanical properties. This results from the precipitation of intermetallic $\gamma^{\prime \prime}$ or $\delta$ particles, with a stronger impact of $\gamma^{\prime}$ ' particles. It is here unambiguously demonstrated a $\delta$ hardening on the RT static properties.

As a second main conclusion, the $\gamma$ " precipitation improves the YS and UTS (up to a factor of two for the YS) and decreases the ductility in the RT $-750^{\circ} \mathrm{C}$ temperature range. Upon testing at $800^{\circ} \mathrm{C}$, the alloy recovers its as-received tensile properties both in terms of YS, UTS and strain to failure due to the dissolution of $\gamma^{\prime \prime}$ particles. It clearly indicates that grain boundary secondary carbides precipitation has no impact on the alloy's HT ductility.

Finally, the increase in static properties at $650^{\circ} \mathrm{C}$ and $750^{\circ} \mathrm{C}$ due to the $\gamma^{\prime \prime}$ precipitation leads to improved LCF properties. This results from a slower cyclic ratcheting under these conditions where high mean stress were imposed. It has also been shown that the $\gamma^{\prime \prime}$ precipitation and the $\gamma^{\prime \prime} \rightarrow \delta$ transformations are faster under cyclic deformation conditions. 


\section{Acknowledgements}

The SAFRAN group (Aircelle, Snecma and Turbomeca companies) is gratefully acknowledged for financial support, for providing the material and for L. Mataveli Suave Master thesis grant.

\section{References}

1. H.L. Eiselstein and D.J. Tillack. "The invention and definition of Alloy 625", (Paper presented at Superalloys 718, 625 and Various Derivatives, Pittsburgh, PA, USA, 1991), 114.

2. L.E. Shoemaker. "Alloys 625 and 725: trends in properties and applications", (Paper presented at Superalloys 718, 625, 706 and Derivatives, Pittsburgh, PA, USA, 2005), 409418.

3. C. Vernot-Loier and F. Cortial. "Influence of heat treatments on microstructure, mechanical properties and corrosion behaviour of Alloy 625 forged rod", (Paper presented at Superalloys 718, 625 and Various Derivatives, Pittsburgh, PA, USA, 1991), 409-422.

4. J.M. Rakowski et al. "The use and performance of wrought 625 Alloy in primary surface recuperators for gas turbine engines", (Paper presented at Superalloys 718, 625, 706 and Derivatives, Pittsburgh, PA, USA, 2005), 271-286.

5. V. Shankar, K.B.S. Rao, and S.L. Mannan, "Microstructure and mechanical properties of Inconel 625 superalloy", Journal of Nuclear Materials, 288 (2001), 222-232.

6. M. Sundararaman et al., "Precipitation of an intermetallic phase with $\mathrm{Pt}_{2} \mathrm{Mo}$-type structure in Alloy 625", Metallurgical and Materials Transactions A, 30A (1999), 41-52.

7. C. Thomas and P. Tait, "The performance of Alloy 625 in long-term intermediate temperature applications", Int. J. Pres. Ves. \& Piping, 59 (1994), 41-49.

8. M. Sundararaman, P. Mukhopadhyay, and S. Banerjee. "Influence of intermetallic phase precipitation during prolonged service in Alloy 625 on its properties", (Paper presented at Superalloys 718, 625, 706 and Various Derivatives, Pittsburgh, PA, USA, 2001), 367-378.

9. H.C. Pai and M. Sundararaman. "A comparison of the precipitation kinetics of $\gamma$ " particles in virgin and re-solutioned Alloy 625", (Paper presented at Superalloys 718, 625, 706 and Derivatives, Pittsburgh, PA, USA, 2005), 487-495.

10. V. Shankar et al., "Room temperature tensile behavior of service exposed and thermally aged service exposed Alloy 625", Scripta Materialia, 44 (2001), 2703-2711.

11. C.R. Conder, G.D. Smith, and J.F. Radavich. "Microstructural and mechanical property characterization of aged Inconel alloy 625LCF", (Paper presented at Superalloys 718, 625, 706 and Various Derivatives, Pittsburgh, PA, USA, 1997), 447-458. 
12. F. Cortial, J.M. Corrieu, and C. Vernot-Loier, "Influence of heat treatments on microstructure, mechanical properties, and corrosion resistance of weld Alloy 625", Metallurgical and Materials Transactions A, 26A (5) (1995), 1273-1286.

13. N.D. Evans et al., "Microstructure evolution of alloy 625 foil and sheet during creep at $750^{\circ} \mathrm{C}^{\prime \prime}$, Materials Science and Engineering A, A498 (2008), 412-420.

14. S. Floreen, G.E. Fuchs, and W.J. Yang. "The metallurgy of Alloy 625", (Paper presented at Superalloys 718, 625, 706 and Various Derivatives, Pittsburgh, PA, USA, 1994), 13-37.

15. U. Heubner and M. Köhler. "Effect of carbon content and other variables on yield strength, ductility and creep properties of Alloy 625", (Paper presented at Superalloys 718, 625, 706 and Various Derivatives, Pittsburgh, PA, USA, 1994), 479-488.

16. J.F. Radavich and A. Fort. "Effects of long-time exposure in Alloy 625 at $1200^{\circ} \mathrm{F}, 1400^{\circ} \mathrm{F}$ and $1600^{\circ} \mathrm{F}$, (Paper presented at Superalloys 718, 625, 706 and Various Derivatives, Pittsburgh, PA, USA, 1994), 635-647.

17. L. Mataveli Suave et al., "Microstructural evolutions during thermal aging of Alloy 625: impact of temperature and forming process", Metallurgical and Materials Transactions A, 45A (7) (2014), 2963-2982

18. M. Köhler. "Effect of the elevated-temperature-precipitation in Alloy 625 on properties and microstructure", (Paper presented at Superalloys 718, 625 and Various Derivatives, Pittsburgh, PA, USA, 1991), 363-374.

19. L. Mataveli Suave, "Etude métallurgique du vieillissement de l'Inconel 625 et de ses répercussions sur les propriétés mécaniques", (M.Sc thesis, ISAE-ENSMA, 2012).

20. M. Sundararaman, P. Mukhopadhyay, and S. Banerjee. "Carbide precipitation in nickel base superalloys 718 and 625 and their effect on the mechanical properties", (Paper presented at Superalloys 718, 625, 706 and Various Derivatives, Pittsburgh, PA, USA, 1997), 367-378.

21. G.D. Smith and D.H. Yates. "Optimization of the fatigue properties of Inconel Alloy 625", (Paper presented at Superalloys 718, 625 and Various Derivatives, Pittsburgh, PA, USA, 1991), 509-517.

22. M. Sundararaman, P. Mukhopadhyay, and S. Banerjee, "Precipitation of the $\delta-\mathrm{Ni}_{3} \mathrm{Nb}$ Phase in Two Nickel Base Superalloys", Metallurgical Transactions A, 19A (1988), 454-465.

23. M. Detrois, R.C. Helmink, and S. Tin, "Hot deformation characteristics of a polycrystalline $\gamma-\gamma^{\prime}-\delta$ ternary eutectic Ni-basesuperalloy", Material Science and Engineering, A 586 (2013), $236-244$

24. J.K. Chakravartty, J.B. Singh, and M. Sundararaman, "Microstructure and mechanical properties of service exposed Alloy 625 ammonia cracker tube removed after $100000 \mathrm{~h}$ ", Materials Science and Technology, 28 (6) (2012), 702-710. 
25. M. Clavel, D. Fournier, and A. Pineau, "Plastic Zone Sizes in Fatigued Specimens of INCO 718", Metallurgical Transactions A, 6A (1975), 2305-2307. 